\title{
Maternal and Foetal Outcome in Pregnancy with Heart Disease Admitted in Chalmeda Anand Rao Institute of Medical Sciences, Karimnagar
}

\author{
Veladanda Kavitha ${ }^{1}$, Chungi Niharika² \\ 1,2 Department of Obstetrics and Gynaecology, Chalmeda Anand Rao \\ Institute of Medical Sciences, Bommakal, Karimnagar, Telangana, India.
}

\section{ABSTRACT}

\section{BACKGROUND}

Heart disease complicating pregnancy is considered as a high-risk condition. Increased cardiac demands during the course of pregnancy potentially increase morbidity and mortality in women with underlying heart disease. Fifty percent increase in volume of plasma and increase in the risk of thrombosis by 6 times strikes a challenge to pregnant woman with heart disease. Pregnancy state is more prone to risk of infection as it is an immunocompromised condition which can result in increased heart rate eventually deteriorating the cardiac function. We wanted to determine maternal and foetal outcome in pregnant women with heart diseases in terms of foetal complications, maternal complications, and mode of delivery.

\section{METHODS}

A prospective clinical study conducted in Chalmeda Anand Rao Institute of Medical Sciences, Karimnagar for delivery was carried to find out the maternal and foetal outcomes in about 30 cases of pregnancy complicated heart disease. Taking prevalence to be $4 \%(\mathrm{P})$ with confidence interval of $95 \%(\mathrm{Z}=1.96)$ and allowable error (d) $7 \%$, sample size was calculated using formula $Z^{2} P Q / d^{2}$

\section{RESULTS}

Present study revealed heart disease in pregnancy as about $0.48 \%$. Rheumatic heart lesions constituted $56.6 \%$ of the cases. Eleven (36.7 \%) women delivered spontaneously vaginally at term. Caesarean section was performed in 12 cases $(41.2$ $\%$ ). There were 2 maternal deaths. No perinatal deaths were reported.

\section{CONCLUSIONS}

Pregnancy and cardiac lesions affect mutually. Compliance of patient and her family to regular follow up will ensure a safe outcome for mother and foetus and avoid complications by regular checkups with obstetrician and cardiologist.

\section{KEY WORDS}

Cardiomyopathy, Pregnancy, Rheumatic Heart Disease, Maternal Morbidity, Maternal Mortality
Corresponding Author: Dr. Chungi Niharika, D/O Chungi Mohan Chander, 10-3-320/2, Flat No: 301, SMR Habitat, Street No: 4, Road No:7, West Marredpally, Secunderabad - 500026, Telangana, India. E-mail: Niharikachungi94@gmail.com

DOI: $10.14260 /$ jemds/2021/677

How to Cite This Article:

Kavitha V, Niharika C. Maternal and foetal outcome in pregnancy with heart disease admitted in Chalmeda Anand Rao Institute of Medical Sciences, Karimnagar. J Evolution Med Dent Sci 2021;10(38): 3338-3341, DOI: 10.14260/jemds/2021/677

Submission 16-06-2021, Peer Review 10-08-2021, Acceptance 16-08-2021, Published 20-09-2021.

Copyright (C) 2021 Veladanda Kavitha et al. This is an open access article distributed under Creative Commons Attribution License [Attribution 4.0 International (CC BY 4.0)] 


\section{BACKGROUND}

In antepartum and postpartum period maternal morbidity and mortality occurs mostly due to cardiac disease. Cardiac disease in pregnancy is broadly divided into congenital and acquired groups. Cardiomyopathies, RHD and ischemic heart disease come under acquired group. Among all these, rheumatic heart disease is most common in developing countries, whereas cardiomyopathies and congenital heart diseases are more common in developed countries. Mitral stenosis quantifies for around three quarters of all cases.

The overall incidence of heart disease in pregnancy is $<1$ $\%{ }^{1}$ In women with heart disease, the incidence of spontaneous miscarriage and therapeutic abortion increases. Children born to mothers with congenital heart disease have higher risk of the same. The overall risk of inheriting polygenic cardiac disease is $3-5 \%$, as compared to $1 \%$ risk in the general population. ${ }^{2}$ Pregnancy state is more prone to risk of infection as it is an immunocompromised condition which can result in increased heart rate eventually deteriorating the cardiac function. The most important nonobstetric cause of morbidity and mortality during pregnancy is cardiac disorder. Changes in circulatory system during pregnancy with maternal cardiac disease leads to adverse events even death of the mother or foetus. Fifty percent increase in volume of plasma and increase in the risk of thrombosis by 6 times strikes a challenge to pregnant women with heart disease. ${ }^{3}$ In developing countries most of the heart diseases are diagnosed during the pregnancy and they pose potential risk as they lack early therapeutic intervention. ${ }^{4}$ Proper assessment during pregnancy leads to early detection of cardiac diseases. If diagnosed early, and managed properly with multidisciplinary approach, collaboration of a team containing trained obstetricians, cardiologist, anaesthetist, paediatrician and nurse, it results in successful outcome for both mother and child in most of the cases. ${ }^{5}$

In normal individual, hemodynamic changes of normal pregnancy are well tolerated. Whereas in diseased heart, decomposition occurs resulting in increased maternal morbidity and mortality. In such conditions foetus will be compromised as foetal health depends upon the availability and continuous supply of well oxygenated maternal blood. ${ }^{6}$

A limited amount of comprehensive studies are available concerning the pregnancy in heart disease women. ${ }^{7-12}$

\section{Objectives}

To determine outcome in pregnant women with cardiac diseases in terms of foetal complication, maternal complication and mode of delivery.

\section{METHODS}

A prospective study was conducted in the Department of OBG at CAIMS, Karimnagar. Study duration was from January 2020 to January 2021. 30 women with heart disease who were previously established or diagnosed during pregnancy and had given their informed consent were enrolled in the study. Taking prevalence to be $4 \%$ (P) with confidence interval of $95 \%(Z=1.96)$ and allowable error $(d) 7 \%$, sample size was calculated using formula $Z^{2} P Q / d^{2}$. This study was given Ethical clearance by ethical committee (CAIMS/01/IEC/2021/010) and informed consent was taken from the entire group included.

Pregnant women having congenital or acquired cardiac lesions or delivered patients having heart disease (with Ejection Fraction $<50 \%$ in 2D-Echo) who were referred to our hospital were included in the study. Pregnant women with associated medical disorders like diabetes mellitus, pulmonary disease, renal disease or any other endocrinological disease were excluded from this study.

Regular monitoring of cardiac status of pregnant women by physician every month was advised. Institutional delivery was suggested to patients as labour was managed as per cardiac conditions. Patients had to stay for about 8 to 10 days of normal delivery and advised about contraceptives, breast feeding, penicillin prophylaxis then discharged.

Baseline data records included were age, parity, gestational age, cardiac lesions, usage of cardiac medications, auscultating chest and cardiovascular system, assessing systolic functions of right and left ventricles via ECG and echocardiography, vaginal delivery, instrumentation and indication for LSCS.

\section{Statistical Analysis}

Descriptive statistics were done in SPSS version 20.

\section{RESULTS}

30 women with heart disease complicated pregnancy were included. The mean age observed in this study was 24 years. Youngest was 19 years \& eldest was 34 years of age.

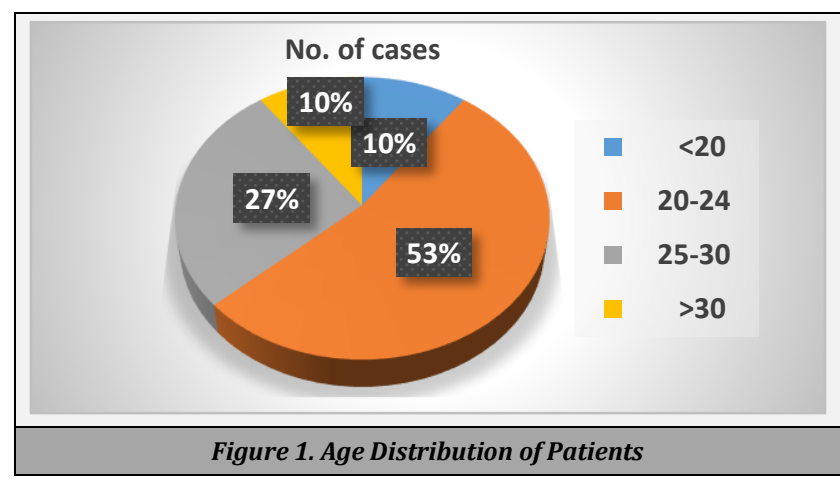

\section{Age Distribution of Patients}

The age of patients ranged from 19 to 34 years with maximum number of patients in 20 - 24 years age group (53 $\%)$. In this study, most of the patients were primigravida.

\begin{tabular}{|ccc|}
\hline Cardiac Lesions & No. of Cases & $\mathbf{\%}$ \\
\hline Rheumatic heart disease & 17 & 56.6 \\
Congenital & 5 & 13.3 \\
Prior cardiac surgery & 2 & 7.8 \\
Peripartum cardiomyopathy & 6 & 22.2 \\
Total & $\mathbf{3 0}$ & $\mathbf{1 0 0}$ \\
\hline Table 1. Distribution of Cardiac Lesion \\
\hline
\end{tabular}

Mitral valve stenosis was the most common lesion found in women with RHD. 


\begin{tabular}{|ccc|}
\hline Pregnancy & No. of Cases & $\%$ \\
LSCS & 12 & 41.2 \\
Vaginal delivery & 11 & 36.7 \\
Instrumental delivery & 3 & 7.8 \\
Termination of pregnancy & 3 & 10 \\
Maternal death & 1 & 4.3 \\
\hline Table 2. Maternal Outcome of Pregnancy in Terms of Mode of Delivery \\
\hline
\end{tabular}

Majority of women were delivered by caesarean section 12 (41.2\%). Eleven (36.7\%) women had natural vaginal delivery (NVD) with spontaneous onset. Three (7.8\%) had assisted instrumental vaginal delivery.

The high rate of $41.2 \%$ of caesarean sections was related to the peculiarities inherent in pregnancy in patients with severe heart disease, associated with retardation of foetal growth, foetal distress, and labour induction risks. In heart disease conditions, wherein which caesarean section was indicated, the aim was to improve the maternal and foetal prognosis in those very dangerous clinical settings by reducing the gestational period. In this event, the procedure was carried out as soon as foetal maturity was established.

\begin{tabular}{|cccccc|}
\hline \multicolumn{7}{c|}{ Complications } \\
Cardiac & No. of Cases & $\mathbf{\%}$ & Non Cardiac & No. of Cases & \% \\
Pulmonary oedema & 7 & 23.3 & Preterm & 10 & 33.3 \\
Atrial fibrillation & 2 & 6.6 & Pre-eclampsia & 6 & 20 \\
Eisenmenger's & 0 & 0 & Anaemia & 4 & 13.3 \\
Death & 2 & 6.6 & PROM & 3 & 10 \\
Thromboembolism & 2 & 6.6 & Oligohydramnios & 2 & 6.6 \\
Cardiac failure & 9 & 30 & Malpresentation & 2 & 6.6 \\
Without & 9 & 30 & Fever & 3 & 10 \\
complications & Table 3. Distribution According to Complications \\
\hline \multicolumn{7}{|l}{} \\
\hline
\end{tabular}

Mostly cardiac complications were seen. Cardiac failure and pulmonary oedema being the highest. Mortality was seen in $6.6 \%$ and $36 \%$ of patients were admitted in medical ICU.

Heart disease was observed to be associated with preeclampsia and anaemia in most cases. Mortality was seen in 2 cases which were mostly contributed by peripartum cardiomyopathy.

\begin{tabular}{|cccc|}
\hline & Perinatal Outcome & Number of Cases & $\%$ \\
LBW babies & Prematurity & 6 & 18.9 \\
& Restriction of foetal growth & 1 & 5.10 \\
& Intrauterine death & 3 & 8.67 \\
NICU admission & LBW & 5 & 17.2 \\
causes & APGAR SCORE at 1minute $<7$ & 1 & 3.4 \\
Causes of & For observation & 3 & 6.8 \\
Neonatal death & Extreme prematurity & 1 & 3.4 \\
\hline \multicolumn{4}{c}{ Birth asphyxia } \\
\hline
\end{tabular}

In perinatal outcome, 3 IUDs (8.6 \%), 7 LBW (24.1\%), 8 had NICU stay (27.5\%), 2 neonatal deaths (5.5\%). There were no perinatal deaths.

\section{DISCUSSION}

Hemodynamic and cardiovascular changes in patients with cardiac lesions lead to deterioration in pregnancy. Socioeconomic status, study population and period of study are the factors that vary the different causes of heart diseases. Prevalence of $0.48 \%$ was found in assessment of maternal and neonatal complications in patients with cardiac malfunctions.

The present study reveals RHD to be 4 times more common than CHD due to inadequate antibiotic treatment for streptococcal infection in childhood as well as adolescence. Only one patient developed failure during puerperium and age group most commonly affected was 20 to 24 years and failure of cardiac functions occurred during 28 - 36 weeks of gestation. 11 patients (36.7\%) delivered spontaneously per vaginum. Labour was spontaneous in all cases. Caesarean section was done only for obstetric indication. There were 3 instrumental deliveries. Termination of pregnancy was opted in 3 cases. Increased incidence of $41.2 \%$ of caesarean sections was due to the peculiarities inherent in pregnancy in patients with severe heart disease, associated with retardation of foetal growth, foetal distress, and labour induction risks.

In this study, $36.7 \%$ women had spontaneous vaginal delivery as compared to $41 \%$ (Nilajkumar et al.) $24 \%$ (Alireza et al.) $76.2 \%$ (Mazhar et al.) $73.5 \%$ (Hameed et al.) $62.8 \%$ (Vidyadhar et al.) in other studies. ${ }^{13,14,15-17}$ Caesarean Section (41.2\%) was done only for obstetrical indications. Nilajkumar et al. reported caesarean in $20.6 \%$; $9.5 \%$ by Mazhar et al. Alireza et al. (76 \%).14,15,16 In the present study, 14 women underwent labour induction as compared to $15 \%$ in a study conducted by Hameed et al. and Pratibha D et al. ${ }^{18,17}$ In the evaluation of pregnancy with cardiac disease, 10 $\%$ had to undergo MTP which was comparable to Suman et al. and Mazhar et al. studies. ${ }^{14,19}$ Cardiac failure and pulmonary oedema were the main causes of mortality in pregnant women with heart disease. Two females in our study died mainly due to cardiac failure, sepsis and shock which was comparable to Hameed et al. Mazhar et al. Alireza et al. Verena et al. Akhtar et al. and Sheetal CN et al.20,14,16,17,19,21

In heart disease complicating pregnancy, in which caesarean was indicated, the aim was to improve the prognosis of mother and foetus, by reducing the period of gestation. The procedure was to be carried out as soon as the foetus was mature. There were $22 \%$ cases of peripartum cardiomyopathy that were shifted to ICU but succumbed, thus there were 2 maternal deaths. The perinatal mortality was nil. In pregnant women with heart disease, a proper, conscious and accurate assessment should be done for maternal and foetal risks. Rheumatic heart disease is the most common heart disease. In this study, we found that incidence of peripartum cardiomyopathy was $22 \%$ which is a rare disease and most of the patients in whom mortality occurred were of peripartum cardiomyopathy. Complication rate and mortality rate associated with cardiomyopathy were $30 \%$ and $20 \%$, respectively, which underestimates the poor prognosis of mothers particularly with left ventricular dysfunction. ${ }^{22}$ Most common \& serious complications of heart disease in pregnancy were cardiac failure, mortality, prematurity \& low birth weight babies.

\section{CONCLUSIONS}

Proper pre pregnancy evaluation and follow up in pregnancy are fundamental for good outcome. This study concluded that the following factors influence the outcome: diagnosis before pregnancy, counselling, referral when needed, routine antenatal care (ANC) and delivery at an equipped centre. Cardiac failure, a serious complication often leads to the death of mother. Therefore there is a need for early detection, monitoring and managing heart failure in pregnancy. 
Data sharing statement provided by the authors is available with the full text of this article at jemds.com.

Financial or other competing interests: None.

Disclosure forms provided by the authors are available with the full text of this article at jemds.com.

\section{REFERENCES}

[1] Bhatla N, Lal S, Behera G, et al. Cardiac disease in pregnancy. Int J Gynecol Obstet 2003;82(2):153-9.

[2] Romano-Zelekha O, Hirsh R, Blieden L, et al. The risk for congenital heart defects in offspring of individuals with congenital heart defects. Clin Genet 2001;59(5):325-9.

[3] Steer P. Heart disease in pregnancy. Women's health medicine. Med Prob Pregnancy 2005;2(2):18-21.

[4] Sawhney H, Aggarwal N, Suri V, et al. Maternal and perinatal outcome in rheumatic heart disease. Int $\mathrm{J}$ Gynecol Obstet 2003;80(1):9-14.

[5] Trinidad D, Cox RA. Heart diseases during pregnancy. P R Health Sci J 2006;25(3):259-65.

[6] Arafeh JM, Baird SM. Cardiac disease in pregnancy. Crit Care Nurs Q 2006;29(1):35-52.

[7] Avila WS, Rossi EG, Ramires JAF, et al. Pregnancy in patients with heart disease: experience with 1000 cases. Clin Cardiol 2003;26(3):135-42.

[8] Siu SC, Sermer M, Harrison DA, et al. Risk and predictors for pregnancy - related complications in women with heart disease. Circulation 1997;96(9):2789-94.

[9] Siu SC, Sermer M, Colman JM, et al. Prospective multicenter study of pregnancy outcomes in women with heart disease. Circulation 2001;104(5):515-21.

[10] Siu SC, Colman JM, Sorensen S, et al. Adverse neonatal and cardiac outcomes are more common in pregnant women with cardiac disease. Circulation 2002;105(18):2179-84.

[11] Abdel-Hady ES, El-Shamy M, El-Rifai AA, et al. Maternal and perinatal outcome of pregnancies complicated by cardiac disease. Int J Gynaecol Obstet 2005;90(1):21-5.
[12] Khairy P, Ouyang DW, Fernandes SM, et al. Pregnancy outcomes in women with congenital heart disease. Circulation 2006;113(4):517-24.

[13] Bangal VB, Singh RK, Shinde KK. Clinical study of heart disease complicating pregnancy. IOSR J of Pharmacy 2012;2(4):25-8

[14] Mazhar SB, Gul-e-Irum. Fetomaternal outcome in pregnancy with cardiac disease. J Coll Physicians Surg Pak 2005;15(8):476-80.

[15] Bagde ND, Bagde MN, Shivkumar P, et al. Clinical profile and obstetric outcome in pregnancies complicated by heart disease: a five year Indian rural experience. Int J Reprod Contracept Obstet Gynecol 2013;2(1):52-7.

[16] Yaghoubi A, Mirinazhad M. Maternal and neonatal outcomes in pregnant patients with cardiac diseases referred for labour in northwest Iran. J Pak Med Assoc 2013;63(12):1496-9.

[17] Hameed A, Karaalp IS, Tummala PP, et al. The effect of valvular heart disease on maternal and fetal outcome of pregnancy. J Am Coll Cardiol 2001;37(3):893-9.

[18] Pratibha D, Kiranmai D, Rani VU, et al. Pregnancy outcome in chronic rheumatic heart disease. J Obstet Gynecol India 2009;59(1):41-6.

[19] Puri S, Bharti A, Puri S, et al. Maternal heart disease and pregnancy outcomes. JK Sci 2013;15(1):7-10.

[20] Sheela CN, Karanth S, Patil CB. Maternal cardiac complications in women with cardiac disease in pregnancy. Int J Pharm Biomed Res 2011;2(4):261-5.

[21] Akhter N, Rahman F, Salman M, et al. Valvular heart disease in pregnancy: maternal and fetal outcome. MMJ 2011;20(3):436-40.

[22] Elkayam U, Ostrzega EL, Shotan A. Peripartum cardiomyopathy. In: Gleicher N, Elkayam U, Galbraith RM, et al. eds. Principles and Practice of Medical Therapy in Pregnancy. $2^{\text {nd }}$ edn. Norwalk, Conn.: Appleton \& Lange 1992:

p.

812-14. 